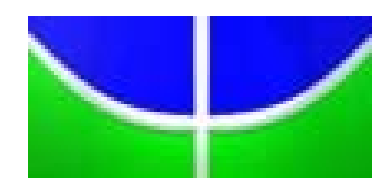

Universidade de Brasília

CET - Centro de Excelência em Turismo

Pós-graduação Lato Sensu

Curso de Especialização em Formação de Professores e Pesquisadores em Turismo e Hospitalidade

\title{
A IMPORTÂNCIA DO MARKETING DE SERVIÇOS NA GESTÃO DO PROFISSIONAL DE TURISMO
}

\author{
LARA MORAES ABRANTES
}

Brasília - DF

Março/2006 


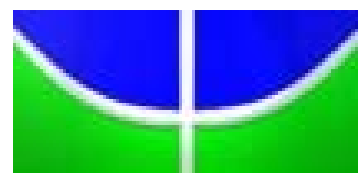

Universidade de Brasília CET - Centro de Excelência em Turismo

\section{A IMPORTÂNCIA DO MARKETING DE SERVIÇOS NA GESTÃO DO PROFISSIONAL DE TURISMO}

Lara Moraes Abrantes

Dra. Tereza Negrão

Professora Coordenadora
MSc Walter Eustaquio

Ribeiro

Professor Orientador
MSc Domingos Spezia

Professor Examinador

"Trabalho apresentado em cumprimento às exigências acadêmicas parciais do curso de pós-graduação lato sensu em Formação de Professores e Pesquisadores em Turismo e hospitalidade para a obtenção do grau de Especialista” 


\section{FICHA CATALOGRÁFICA}

ABRANTES, Lara Moraes.
A IMPORTÂNCIA DO MARKETING DE SERVIÇOS NA
GESTÃO DO PROFISSIONAL DE TURISMO/Lara Moraes
Abrantes.
Monografia - Curso de Especialização em Formação de Professores e
$\quad$ Pesquisadores em Turismo e Hospitalidade
Brasília - DF, março de 2006.
Área de Concentração: Marketing
Orientador: Prof. (Msc) Walter Eustaquio Ribeiro
1. Marketing 2. Turismo 3. Serviços 3. Profissional do turismo




\section{LISTA DE TABELAS}

Tabela 1: Evolução Turística no Mundo: 1950 a 1995......................................31

Tabela 2: Chegada de Turistas Estrangeiros no Brasil: 2003.......................... 34

Tabela 3: Saídas de Turistas Brasileiros: 2003.................................................... 35 


\section{DEDICATÓRIA}

Dedico esta monografia a toda minha família que sempre esteve ao meu lado. 


\section{AGRADECIMENTOS}

A Deus, por sua infinita bondade e proteção, dando-me forças para concluir, mas essa jornada.

Aos mestres, que contribuíram para nosso aprendizado, partilhando seus conhecimentos, vivencias e atenção.

À turma maravilhosa, com a qual convivemos por treze meses. 
"Um serviço é qualquer atividade ou beneficio que uma parte possa oferecer a outra que seja essencialmente inatingível e que não resulte em propriedade de coisa alguma”. (Kolter, 1988). 


\section{RESUMO}

O presente trabalho monográfico tem a intenção de investigar, à luz da teoria dos serviços no turismo, como a utilização do marketing serviço poderia melhorar os padrões de atendimento, objetivando, com isso, um melhor rendimento e um aumento na receita das empresas de turismo. Com base nisso, procurou-se, sobretudo, verificar a importância do marketing de serviços na gestão do profissional de turismo, tentando estimular a prática do marketing de serviços na gestão desse profissional. Além do mais, as questões referentes à qualidade desses serviços foram, ao longo do trabalho, bastante enfatizadas, procurando, com isso, evidenciar que, no processo de gestão do turismo, o profissional especializado tem condições de estimular com muita propriedade essa prática discutida nesse trabalho de pós-graduação.

Palavras-chave: 1. Marketing 2. Turismo 3. Serviços 3. Profissional do turismo 


\section{ABSTRACT}

The present paper has the intention to investigate, to the light of the theory of the services in the tourism, as the use of the marketing of the tourism could improve the service patterns, aiming at, with that, a better income and an increase in the income of the companies of tourism. According that, it was sought, above all, to verify the importance of the marketing of services in the professional's of tourism administration, trying to estimulate the practice of the marketing of services in that professional's administration. Besides, the subjects regarding the quality of those services were, along the work, quite emphasized, seeking, this way, to evidence that, in the process of administration of the tourism, the specialized professional has conditions of stimulating with a lot of property that practice discussed in that masters degree work.

Word-key: 1. Marketing 2. Tourism 3. Services 3. Professional of the tourism 


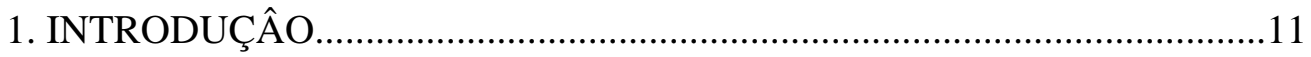

2. DELIMITAÇÃO DO ESTUDO …..................................................13

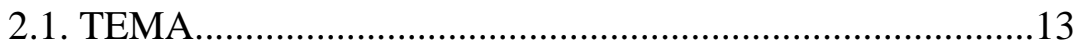

2.2. Objetivos …................................................................ 13

2.2.1 Objetivos Gerais .......................................................... 13

2.2.2 Objetivos Específicos .................................................... 13

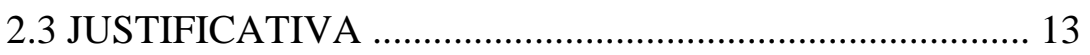

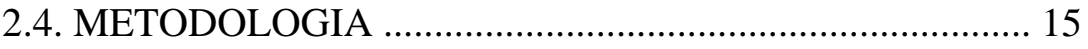

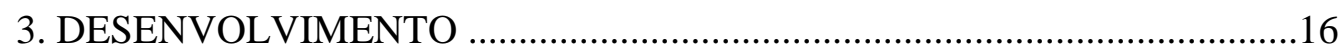

3. REVISÃO DE LITERATURA.......................................................16

3.1. Conceito de Marketing .......................................................16

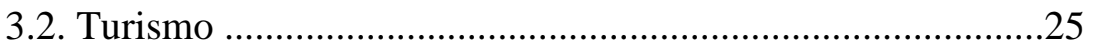

3.3. Marketing de Serviços ...................................................... 38

3.4. Conceito e Serviços ..............................................................40

3.5. Tipos de Serviços ............................................................. 43

3.5.1. Serviços de Consumo.........................................................43

3.5.2. Serviços Industriais ..........................................................4

3.6. Características dos Serviços ............................................... 44

3.7. Componentes do Pacote de Serviços .....................................46

3.8. Distribuição dos Serviços .................................................... 47 


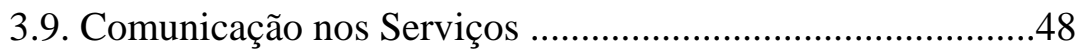

4. GESTÃO DA QUALIDADE DOS SERVIÇOS ..........................................50

CONSIDERAÇÕES FINAIS .................................................... 55

REFERÊNCIAS BIBLIOGRÁFICAS ....................................... 56 


\title{
1. INTRODUÇÃO
}

Muitos empreendedores estão se perguntando: o que devemos fazer para nos manter diante de um mercado tão competitivo? Muitos acham que a solução está em tecnologia de ponta, talvez esteja para alguns empreendedores, mas para muito deles a tecnologia não é mais um diferencial, e sim uma necessidade. Diante de um mundo globalizado o que ainda é um diferencial é a prestação e serviço. Os clientes estão cada vez mais exigentes na área de serviços, o nível de insatisfação ainda é maior, pois em virtude de serem raros os bons profissionais prestadores de serviço, a área apresenta grandes oportunidades e desafios.

Sendo o turismo uma indústria que tem como essência a prestação de serviços, vimos que é de grande importância, abordar alguns temas como: marketing, marketing de serviços, gestão de serviços, turismo e marketing de serviços no turismo. Para tanto, vejamos:

\begin{abstract}
O turismo constitui-se em um fenômeno que só existe em razão de sua interdisciplinaridade, portanto é resultado da intercessão de várias outras atividades que tem como núcleo comum à categoria trabalho. Nesse sentido, para entendermos teoricamente o turismo necessitamos compreender as condições do mundo do trabalho em sua dimensão política e econômica. (BARRETO, 1995: colocar página?).
\end{abstract}

O turismo certamente surgiu com o aparecimento do homem, quando este se tornou nômade, motivado por questões de sobrevivência. Após a exploração de determinada localidade, havia a necessidade da busca de novos locais.

A importância do setor de serviços tende a ser tanto maior quanto mais desenvolvida é a economia de um país. O Brasil apresenta uma grande 
participação do setor de serviços tanto em temos de índices econômicos, quanto em importância relativa frente aos outros setores da atividade econômica.

Tem-se no setor de serviços, o turismo, que está entre a terceira ou quarta atividade de maior crescimento no mundo, estimulado pela globalização que a detecta como um dos setores ainda pouco explorados, porém com uma potencialidade de crescimento que supera todos os outros campos.

Essa dimensão expansionista em que a mercadoria (turismo) se concretiza no interior dos sistemas econômicos estão acima de qualquer opção política ideológica, pois todas dependem do capital. Nesse sentido, buscam implementar os processos de acumulação. No capitalismo, o turismo assume os primeiros postos como uma das atividades econômicas de maior rentabilidade, fabricam-se ilusões, criam-se estilos de vida, cultiva-se o hábito pelo descanso no período do não trabalho e cada vez mais se tem a certeza que o turismo se constitui em uma das atividades em que o Estado pode recorrer para diminuir a sua crise neoliberal.

De acordo com Serson (2000), as perspectivas de crescimento do turismo global são $23 \%$ maiores do que as de crescimento da economia mundial. Hoje a participação do setor de serviços no PIB supera 50\%, sendo que as atividades relacionadas ao turismo estão entre as mais importantes do setor. 


\section{DELIMITAÇÃO DO ESTUDO}

\subsection{TEMA}

A importância do marketing de serviços na gestão do profissional de turismo.

2.2 OBJETIVOS

\subsubsection{OBJETIVO GERAL}

- Verificar a importância do marketing de serviços na gestão do profissional de turismo

\subsubsection{OBJETIVOS ESPECÍFICOS}

- Estimular a prática do marketing de serviços na gestão do profissional de turismo;

- Proporcionar uma visão abrangente e integrada da gestão dos serviços;

- Discorrer sobre a qualidade nos serviços.

\subsection{JUSTIFICATIVA}

O Brasil dispõe de um produto cobiçado no mundo inteiro, a combinação de sol e mar em praticamente todo ano, numa grade extensão costeira, animado pela hospitalidade de um povo alegre e um país rico em cultura e ambiente, dos recursos naturais, materiais e históricos. O maior parque ecológico do mundo, 
entre outras maravilhas, que devem ser exploradas de forma coordenada pelo turismo, de olho no fator multiplicador que esta atividade proporciona.

O turismo constitui fator indispensável à estabilidade da economia nacional, contribui para a captação de divisas e proporciona trabalho a milhares de pessoas, tendo deixado de ser uma atividade secundária, envolvendo uma pequena fração de produtores e consumidores.

Nos dias atuais, um dos ramos do serviço que mais crescem no mundo é o turismo. Segundo Gil Nuno Vaz (2001:7) o turismo é uma atividade econômica que mobiliza mais de 50 setores produtivos de bens e serviços, requerendo o trabalho de inúmeras categorias técnicas e profissionais. Pelo exposto, dá para perceber que a atividade turística é baseada principalmente em serviços.

Para Marcos Cobra e Flávio Zwarg (1987:3) "marketing de serviços é uma disciplina que procura estudar os fenômenos e fatos que ocorrem na venda dos serviços". Entende-se como serviço uma mercadoria comercializável isoladamente, ou seja, um produto intangível que não se pega, não se cheira, não se apalpa, geralmente não se experimenta antes da compra, mas permite satisfações que compensam o dinheiro gasto na realização de desejos e necessidades dos clientes.

Outra característica do serviço é a simultaneidade da fabricação e consumo. O serviço não pode ser estocado e é consumido conforme é produzido. Portanto, o turista que compra um pacote de viagem para a Pousada do Rio Quente, em Goiás, não pode "guardar" os serviços que serão prestados naquele ato para consumir posteriormente. Após o término do pacote, o serviço será finalizado e nada poderá ser aproveitado posteriormente. 
Pensando nesses tópicos acima, senti a necessidade de realizar um estudo sobre a importância, da utilização do conceito de marketing de serviços no turismo, para a padronização do atendimento e a melhoria da qualidade, numa tentativa de aumentar as receitas.

\subsection{METODOLOGIA}

Este trabalho, buscou alcançar os objetivos gerais e específicos mediante a utilização de pesquisa bibliográfica, por se mostrar a mais adequada para os fins dessa monografia, que é o levantamento de dados atualizados sob o tema em questão. Para tanto, foram consultados livros especializados, sites da internet, entre outras fontes de pesquisas disponíveis 


\section{REVISÃO DE LITERATURA}

\subsection{CONCEITUAÇÃO DE MARKETING}

Para entender o marketing, torna-se útil compreender sua evolução ao longo do tempo, pois a diversidade de significados relacionada a esse termo gera não só uma diluição conceitual como o emprego inadvertido de um mesmo conceito para designar práticas diferentes. Sendo assim, este capítulo traz evolução do conceito de marketing.

Numa linha evolutiva, Richers (2000) descreve que o marketing passou da preocupação com a maximização dos lucros no curto prazo ao reconhecimento da importância da satisfação dos desejos dos consumidores. De uma disciplina de gestão empenhada em aumentar as vendas, passa a ser aplicado como uma ciência comportamental concebida a partir do equilíbrio entre sistemas de compra e venda, ou seja, um sistema de troca, agora, atenta para os interesses da sociedade em suas tomadas de decisões.

Segundo Kotler (1998), "marketing é o desempenho das atividades de negócios que dirigem o fluxo de bens e serviços do produtor ao consumidor". Esse conceito prevaleceu durante muito tempo, porém tal definição não resistiu às críticas de inúmeros praticantes de marketing e deu lugar a interpretações cada vez mais voltadas para a responsabilidade das funções administrativas e para a abordagem sistêmica que se preocupava com a integração ordenada entre seus instrumentos.

De acordo com Kotler (2000:30), para definir marketing se faz necessário estabelecer uma distinção entre definições sociais e gerenciais. A definição social 
mostra o papel desempenhado pelo marketing na sociedade, por isso o define como "processo social por meio do qual as pessoas e grupos de pessoas obtêm aquilo que necessitam e o que desejam com a criação, oferta e livre negociação de produtos e serviços de valor com os outros". Por outro lado, a gerencial é definida como "o processo de planejar e executar a concepção, a determinação do preço, a promoção e a distribuição de idéias, bens e serviços para criar trocas que satisfaçam metas individuais e organizacionais".

Ainda segundo Kotler, o mundo dos negócios, desenvolvendo-se com uma velocidade espantosa e ampliando sua gama de transações e distribuição, buscou conhecer mais profundamente a natureza do marketing. A partir de então, os progressos verificados nos estudos de marketing têm ajudado a produzir definições cada vez mais completas.

Segundo Kotler (1998), pode-se destacar que o marketing deve preocuparse com algumas questões fundamentais da atualidade, sejam elas de cunho ambiental, no que se refere à escassez de recursos e a deterioração do meio ambiente, sejam elas de cunho humano, no que se refere à explosão populacional, a fome e a pobreza mundial. Essa ampliação do conceito de marketing propõe, então, que as empresas considerem três dimensões ao definirem suas estratégias: os lucros, a satisfação dos desejos dos consumidores e o interesse público.

As teorias de marketing têm como objetivo ampliar a compreensão científica acerca de determinados fenômenos, por meio de uma estrutura sistematizada, que permita explicá-los e prevê-los. Desse modo, é inegável a importância da construção de teorias para o avanço da ciência. O interesse no desenvolvimento 
dessas teorias tornou-se evidente a partir de 1950 e 1960, quando da situação econômica do início dos anos de 1950 que era extremamente favorável para a consolidação do marketing como filosofia empresarial.

A realidade, naquela época, mostrava os mercados em crescimento, a competição cada vez mais agressiva, com empresas focadas nos seus produtos e capacidades de produção, sendo o marketing dominado pelas funções de vendas enquanto que os consumidores mostravam-se com poder de compra crescente e mais exigentes e criteriosos nas suas escolhas de compra.

Para equilibrar essa relação de forças era necessário surgir uma nova abordagem para a relação das empresas com seus clientes, propiciando o surgimento do conceito de marketing.

Os aspectos filosóficos e práticos do conceito de marketing são abordados por Kotler (1998), como uma filosofia empresarial que assume que a chave para atingir as metas organizacionais consiste em ser mais eficaz do que os concorrentes para integrar as atividades de marketing, satisfazendo, assim, as necessidades e desejos dos mercados alvo. Na visão de Kotler (1998:14), "marketing é muito mais do que o departamento de vendas de uma empresa. Marketing é um processo ordenado e criativo de pensar e planejar para os mercados. Esse processo tem início pesquisando-se o mercado para conhecer sua dinâmica. O processo de marketing, por sua vez, envolve a segmentação do mercado e a escolha daqueles mercados-alvos".

Kotler (1998:) descreve, também, o conceito de marketing na visão tridimensional e informa que o mesmo pode ser entendido como uma atividade realizada na empresa (dimensão funcional), um processo gerencial (dimensão 
administrativa) ou uma maneira ampla de conduzir a empresa (dimensão filosófica). Em relação à dimensão funcional, o marketing pode ser entendido como uma das funções desenvolvidas na empresa, que visa atender simultaneamente aos desejos e necessidades dos consumidores e aos objetivos econômicos da empresa, mediante a oferta de um produto ou serviço.

Do ponto de vista da dimensão administrativa, o marketing consiste na análise, planejamento, implementação e controle de programas destinados a realizar as trocas desejadas com os mercados-alvo, de modo a atingir as metas da organização. Quanto à dimensão filosófica, é correto defini-la como uma atitude, um modo de pensar, uma filosofia que se oriente para o cliente.

Já na opinião de Bernett (1995), marketing é um processo de planejamento e execução da concepção, preço, promoção, e distribuição de idéias, bens, e serviços para criar trocas que satisfaçam os objetivos dos indivíduos e das organizações.

$\mathrm{Na}$ concepção tradicional de Kotler (1998), marketing refere-se a um processo social e gerencial pelo qual indivíduos e grupos obtêm o que necessitam e desejam através da criação, oferta e troca de produtos de valor com outros. Esta definição envolve elementos que não se restringem a processos gerenciais, mas que envolvem também processos sociais, tais como: necessidades, desejos e demandas; produtos; valor; custo e satisfação; troca, transações e relacionamento.

Kotler (1998) ainda acrescenta que o marketing é uma orientação para o cliente que tem como retaguarda o marketing integrado (4 Ps), cujo objetivo é gerar satisfação e, a longo prazo, o bem-estar do consumidor como chave para o 
atendimento das metas organizacionais. Nesse caso, as empresas devem avaliar constantemente se estão praticando marketing de forma ética e socialmente responsável. O autor sugere uma reflexão sobre técnicas de vendas que invadem a privacidade das pessoas, técnicas de pressão para forçá-las a comprar e a aceleração da obsolescência de bens. De acordo com essa visão, o autor propõe uma ampliação da concepção tradicional de marketing, definindo-o como marketing societal, ou seja:

\footnotetext{
o marketing societal define a tarefa da organização como sendo de determinar necessidades, desejos e interesses de participação de mercado e proporcionar a satisfação desejada mais efetiva e eficientemente do que a concorrência, de forma a preservar ou aumentar o bem estar do consumidor e da sociedade (KOTLER, 1998:44).
}

Ainda em relação ao conceito de marketing, Vavra (1993:26) destaca alguns elementos-chave, são eles:

1. Seleção de um mercado ou mercados-alvo;

2. Identificação dos desejos, necessidades e demandas de um grupo selecionado de mercado;

3. Combinação de produtos, bens e serviços existentes ou novos para atender esses desejos, necessidades e demandas;

4. Entrega de satisfação;

5. Estabelecimento e administração de um processo de mudança para fixar preço, promover e entregar produtos, bens ou serviços logisticamente;

6. Antecipação da mudança que ocorrerá no mercado-alvo e no ambiente.

Esses elementos, segundo o autor, descrevem uma perspectiva que pode ser chamada marketing de conquista. A partir dessa perspectiva, Vavra (1993:27) 
informa que as prioridades das empresas têm sido "identificar um mercado-alvo, determinar as necessidades dos mercados-alvo, combinar um produto ou serviço que elas possam produzir para atender às necessidades do mercado e atrair um número máximo de consumidores no mercado-alvo para experimentar o produto ou serviço".

Nickels e Wood (1999:9) conceituam marketing como "a idéia de que as organizações podem satisfazer seus objetivos de longo prazo, como a lucratividade, coordenando e concentrando todas as suas atividades na identificação e satisfação das necessidades e desejos dos consumidores. Esse conceito se baseia em uma orientação para o cliente, à coordenação e integração de todas as atividades de marketing e, uma orientação para o lucro.".

Grönroos (1993:164) conceitua marketing como sendo um fenômeno que pode ser abordado de muitas formas. Em ordem de importância, compreende:

um estado de espírito ou uma filosofia que orienta o pensamento geral da organização, tanto no processo de tomada de decisão quanto na execução dos planos acordados; uma maneira de organizar as várias funções ou atividades da empresa; e um conjunto de ferramentas, técnicas e atividades, que os clientes e o público da organização em geral estão expostos.

Ruschmann (1999:15) conclui que as definições de marketing devem convergir para a questão gerencial, na qual a coordenação e estruturação das decisões tomadas por uma empresa baseiam-se nas necessidades e desejos do consumidor.

Considerando o exposto, nota-se que todos os autores fazem referência a três aspectos do conceito de marketing: orientação para o cliente, marketing coordenado e lucratividade. Alguns enfatizam o aspecto filosófico/empresarial e 
outros buscam suas dimensões operacionais, visando analisar os facilitadores e as barreiras à sua implantação, inclusive quanto à estrutura e funcionamento da organização. Observa-se, também, que o conceito de marketing, surgido nos anos 50, foi sendo estruturado visando transformar-se de uma proposição filosófica para um esquema conceitual que se refletisse em práticas de marketing implementáveis. Consolidou-se, no inicio dos anos 90, nos modelos que avaliam o grau de orientação para o mercado tomando como parâmetro o grau de adoção e implantação do conceito de marketing. (KOTLER, 1998 e 2000; VAVRA, 1993; GRÖNROOS, 1993; NICKELS e WOOD, 1999).

Conforme McCarthy e Perreault (1997) as decisões para o planejamento estratégico de Marketing são muito importantes para o sucesso de uma empresa. Entretanto, nem sempre marketing foi tão complicado. Marketing pressupõe a compreensão das necessidades, percepções, preferências e interesse pela satisfação e pelos os padrões de comportamento da audiência-alvo, além da adequação das mensagens, da mídia, dos custos e das facilidades, a fim de maximizar suas atividades na área em que é aplicado.

Modernamente, as novas tecnologias aplicadas à informação permitem que enormes e variadas quantidades de dados sobre pessoas, tanto físicas quanto jurídicas, sejam armazenadas em banco de dados de relevantes informações.

Essa evolução, associada às técnicas mercadológicas, torna possível agrupar consumidores por dados de similaridade que possibilitam planejar as mais diferentes operações e atividades de marketing. O novo marketing é o marketing de relacionamento continuado entre uma empresa e uma pessoa física (física ou 
jurídica - business-to-business ${ }^{1}$ ), que possibilita a mútua satisfação de interesses com a efetivação de troca e repetição contínua. Nessa nova, era o marketing de relacionamento adotado pelas empresas de maior visão será um grande diferencial competitivo; um método de melhor servir e melhor manter clientes ativos.

Apresentaremos três estágios de evolução em direção ao Marketing moderno, a era da produção, a era de vendas, a era do departamento de Marketing e a era da empresa de Marketing. Os mesmos autores falam sobre essas áreas como se fossem aplicadas a todas as empresas, mas tendo em mente que alguns gerentes não alcançaram os estágios finais. Estão presos no passado com formas antiquadas de pensamento.

1. Da era de produção à era de venda: desde o término da revolução industrial em 1840 até os anos vinte do século passado, as empresas se encontravam na era da produção. Devido à escassez de produtos no mercado, durante este estágio a forma de pensar era "se pudermos fabricálo o venderemos". No início da década de 30, a produção deixou de ser o principal problema da maioria das empresas dos países ocidentais industrializados. A ênfase passou a ser sobre as vendas em virtude do aumento da concorrência.

2. Da era de venda à era do departamento de Marketing: até a década de cinqüenta ainda prevalecia a era de vendas. As vendas, nesse período,

\footnotetext{
${ }^{1}$ Significa negócio a negócio.
} 
aumentavam rapidamente na maioria dos setores econômicos. Foi quando surgiu a necessidade de conciliar os esforços de pesquisa, compra, produção, embarque e vendas em um único departamento, o de Marketing.

3. Da era do departamento de marketing à era da empresa de marketing: a partir de 1960, a maioria das empresas passou a desenvolver pelo menos um grupo de pessoas com visão de administração de marketing, evoluindo do departamento de marketing para a era da empresa de marketing. Para Mccarthy e Perreault (1997:35): "a era da empresa de marketing existe quando, além do planejamento de marketing em curto prazo, a equipe de marketing desenvolve planos em longo prazo — às vezes, para dez anos ou mais - e o esforço total da empresa é orientado pelo conceito de marketing".

Atualmente, vive-se a era virtual, na qual se fala em marketing na Internet. Mccarthy e Perreault (1997:38) dizem que do ponto de vista do consumidor, o marketing na Internet apresenta duas grandes novidades: uma maior liberdade de escolha e a eliminação por completo da barreira distância. Fala-se, também, em CRM que em inglês significa gestão do relacionamento com os clientes; aparece como ferramenta tecnológica, tratando cada cliente como se fosse único.

\subsection{TURISMO}

Para bem compreender o turismo moderno, é preciso fazer referência à história dos deslocamentos humanos ao longo dos tempos, feitos por vontade 
própria e com fins diversos. A partir do momento em que começaram os estudos científicos do turismo, muitas definições têm sido dadas, tanto para turismo quanto para turista.

Registram-se na Antigüidade três grandes motivações por viagens: curiosidade, interesse político e comercial e o sentimento religioso. O aspecto político provocava viagens entre os governos dos diferentes Estados, para manter relações que visavam estabelecer entendimentos e identidade política. No setor comercial, eram empreendidas longuíssimas viagens como as dos mercadores.

O sentimento religioso levava também pessoas a percorrerem milhares de quilômetros. Como é o caso dos chineses, adeptos de Buda, que iam a Índia e a outros países.

O fenômeno turístico está relacionado com as viagens, no qual as pessoas visitam locais diferentes ao de suas residências. Assim, Ignarra (1999) explica que as viagens em termos históricos iniciaram-se quando o homem deixou de ser sedentário e passou a viajar, principalmente motivado pela necessidade de comércio com outros povos. É aceitável, portanto, admitir que as viagens de negócios antecederam às viagens de lazer, era também econômica a motivação para as grandes viagens exploratórias dos povos antigos, que buscavam conhecer novas terras para sua ocupação e posterior exploração.

Dessa maneira, o turismo de negócios data de milênios, antes de Cristo. A motivação religiosa também foi responsável por viagens na Idade Média, através das Cruzadas.

Como se vê, o hábito de viagens para outras localidades por inúmeros motivos é um fenômeno antigo na história da humanidade, pois as viagens sempre 
foram ações que se originaram de um contexto do qual está inserida a sociedade em um determinado momento histórico. Representa um dos elementos componentes da vida econômica e social dos homens no decorrer de cada época e para cada civilização, no qual o sentido das viagens realizadas adquiriu significados distintos dos atuais. De acordo com Ignarra (1999:15), entre os séculos II e III houve intensa peregrinação à Jerusalém, à Igreja do Santo Sepulcro, que foi construída em 326 pelo Imperador Constantino, o Grande. A partir do século VI, aproximadamente, registram-se peregrinações de cristãos (chamados romeiros) para Roma. No século IX, foi descoberta a tumba de Santiago de Compostela, e tiveram início as peregrinações dos chamados Jacobitas ou Jacobeus. Tais peregrinações eram feitas por terra e por mar, e também havia os budistas para o extremo Oriente.

Conforme Ignarra (1999:5), no fim da Idade Média, com o advento do capitalismo comercial criaram-se extensas vias de circulação ao longo do território europeu. No entroncamento dessas vias, surgiram as grandes feiras de trocas de mercadorias. Tratava-se, portanto, do início das feiras que hoje grande fluxo de turismo provocam no mundo todo. No Renascimento, com a ênfase dada as artes, ciência e letras, e com a habilidade do povo lusitano em empreender viagens marítimas, as descobertas, curiosidades e a busca de novidades impulsionaram uma onda de viagens.

Lickorish e Jenkins (2000) destacam que a reforma e a secularização do ensino estimularam o movimento. No século XVII, viajar já estava se tornando aceitável como parte da educação de cavalheiros. Os jovens de boas famílias que ansiavam por carreiras de administradores, advogados ou soldados, eram 
incentivados a viajar para o exterior, como uma versão anterior do grand tour, muitas vezes retornando um tanto desgastados. Argumentos contra e a favor do valor de tal "turismo" eram comuns. Lord Shaftesbury previu que os jovens retornariam para enriquecer seu próprio país com os benefícios de suas viagens, uma vez que seria por meio delas que poderia se verificar o que os países vizinhos estavam fazendo e certamente o nosso país seria enriquecido por meio de outras aquisições e novas formas de comércio. Constata-se com isso que o debate sobre o custo-benefício do "turismo" teve seu início há muitos anos.

Segundo Trigo (1998:12) "o turismo organizado surge a partir de meados do século XIX, como conseqüência do desenvolvimento tecnológico iniciado pela Revolução Industrial e da formação de parcelas da burguesia comercial e industrial com tempo, dinheiro e disponibilidade para viajar."

Todavia, Barreto (1995:página????) afirma que para uma melhor compreensão da história do turismo é essencial retornar a diferença entre o conceito de viagem, que implica apenas deslocamento, e o conceito e turismo, que implica a existência também de recursos e infra-estrutura. Cabe destacar que com o advento das ferrovias no século XIX propiciou deslocamentos a distâncias maiores em períodos de tempos menores. Com isso, o turismo ganhou grande impulso. Na Inglaterra, desde 1830 já existiam linhas férreas que transportavam passageiros.

Em 1841, Thomas Cook organizou uma viagem de trem para 570 passageiros entre as cidades de Lancaster e Lougboroug, na Inglaterra. A viagem foi um sucesso e a empresa de Thomas Cook prosperou e passou a ser considerada a primeira agência de viagens do mundo. (IGNARRA, 1999:15) 
As viagens marítimas também se desenvolveram bastante nesse período. Com o advento dos barcos a vapor na Segunda metade do século XVIII, a navegação passou a ser mais segura, mais rápida e com maior capacidade de carga e de passageiros. "Assim, as viagens intercontinentais passaram a ser viáveis comercialmente e se iniciou um grande intercâmbio turístico, principalmente entre a Europa e os demais continentes." (IGNARRA, 1999:19) Em 1924, foi criada a União Internacional de Organizações Oficiais para a Propaganda Turística, cujo primeiro congresso foi celebrado na cidade de Haia, em 1925. Cinqüenta anos mais tarde, essa organização deu origem à Organização Mundial do Turismo (OMT). Lickorish e Jenkins (2000), ao falar de turismo, o dividem em quatro estágios:

1. Turismo pré-histórico - compreende ao longo período da era medieval e o inicio do século XVII, quando os primeiros sinais do crescimento industrial começaram a afetar o modo de vida estabelecido durante os séculos. $\mathrm{O}$ aumento gradual da riqueza, a extensão das classes de comerciantes e profissionais, os efeitos da Reforma e a secularização da educação estimularam o interesse por outros países e a aceitação da viagem em si como um elemento educacional.

2. Transporte - a era das ferrovias representou o segundo estágio, quando os trens e navios a vapor transformaram as oportunidades de viagens. Inventou-se a viagem em massa e, com ela, o desenvolvimento de resorts e a introdução da industria de viagens, formada por agências e operadoras de turismo, com novos métodos de marketing. Embora o transporte fosse 
um fator importante no crescimento, havia outros elementos essenciais e também alguns problemas, pois, como hoje em dia, a coordenação dos planos de transporte e das políticas e projetos do turismo eram limitadas ou inadequadas.

3. O período entre guerra - o terceiro estágio é representado pelo período entre 1918 a 1939. Como é sabido, a guerra impulsionou algumas formas de desenvolvimento técnico muito úteis em um prazo maior, com a expansão notável das rodovias e um considerável investimento na aviação. Entretanto, essa, foi, acima de tudo, a era dos automóveis. Foram lançadas novidades no que se pode chamar de turismo social, com o aumento das férias pagas, o aumento da variedade de lazer recreativas e atividades especializadas, transporte barato e turismo com ônibus fretados.

4. A decolagem do turismo - o período de 1945, dois anos pós-guerra até o presente momento, representa o quarto estágio. Essa é um era de revolução na tecnologia, de mudanças e desenvolvimento industrial em massa, resultando em uma aceleração quanto à criação de riquezas e ao escalonamento de rendas disponíveis. Os avanços tecnológicos no transporte e em outras formas de comunicação reforçaram ainda mais os fatores econômicos que favoreceram a expansão do turismo.

Na primeira metade deste século, o turismo teve momentos de altos e baixos devido a I e II Guerras Mundiais, e a crise de 1929. Somente em 1949, o turismo renasce, então com características crescentes de turismo de massa. Em 1949, 
cerca de 9 milhões de pessoas viajaram para outros países e, a partir desse ano, o volume significativamente, como pode ser observado na tabela 1.

\begin{tabular}{l|l|l}
\hline ANO & TURISTAS (MILHÕES) & RECEITA (US\$ BILHÕES) \\
\hline 1950 & 20,0 & - \\
1953 & 23,0 & - \\
1959 & 63,0 & 6,9 \\
1960 & 69,3 & - \\
1963 & 96,0 & - \\
1964 & 110,0 & 11,6 \\
1965 & 112,7 & 17,9 \\
1970 & 159,7 & 40,7 \\
1975 & 214,4 & 102,4 \\
1980 & 284,8 & 116,2 \\
1985 & 322,7 & 230,0 \\
1990 & 425,0 & 444,0 \\
1995 & 641,0 & \\
\hline
\end{tabular}

Tabela 1 - Evolução Turística no Mundo: 1950 a 1995

Fonte: Trigo, 1998, p. 16.

É importante destacar que pela dimensão do turismo como fator de desenvolvimento, integração social, cultural e de união entre os povos, a Organização das Nações Unidas (ONU) criou em 1975 a Organização Mundial do Turismo (OMT), órgão responsável pela coleta de dados e análise do turismo mundial. 
Ignarra (1998) destaca que o advento da aviação deu o impulso definitivo para o desenvolvimento do turismo. A avaliação em menos de um século evoluiu muito rapidamente, tomando as viagens bem mais rápidas e baratas, possibilitando, assim, um grande intercâmbio turístico.

De acordo com Ignarra (1998) no Brasil, a história das viagens começa com o seu próprio descobrimento. As primeiras expedições não deixavam de estar fazendo turismo de aventuras.

Com a instalação das capitanias hereditárias e do Governo Gera,I criaramse as viagens de negócios entre a metrópole e a colônia. Relatos históricos mostram que, na segunda metade do século XVIII, não havia nem hospedarias na cidade do Rio de Janeiro.

No início do século XIX, a corte portuguesa transfere-se para o Brasil e com isso há grande desenvolvimento urbano, notadamente no Rio de Janeiro. Cresce a demanda por hospedagem na cidade em função da visita de diplomatas e de comerciantes, iniciando-se, assim, a hotelaria brasileira.

Segundo Barreto (1995:59), "o turismo como fenômeno social começou depois de 1920. Pode-se traçar um marco com a criação da Sociedade Brasileira de Turismo, em 1923, que depois se tornaria Touring Clube. O turismo surgiu vinculado ao lazer; nunca teve cunho de aventura ou educativo como na Europa". Em 1927, a empresa aérea Lufthansa cria no Brasil a Condor Syndicat que mais tarde daria vida à empresa de aviação brasileira Varig. Esta empresa e, posteriormente, a Panair do Brasil dão impulso ao turismo interno e externo.

A partir de 1950, grandes contingentes passam a viajar, mas, apesar de ser principalmente um turismo de massa, nunca atingiu o total da população. As 
classes altas consomem turismo particular e as classes médias, turismo de massas.

Em 1966, por meio do Decreto Lei n. ${ }^{\circ} 55$, o Governo Federal reconhece a importância da indústria do turismo para o desenvolvimento econômico do país, criando a Empresa Brasileira do Turismo (EMBRATUR).

Passando a condição de autarquia em 1991, através da Lei n. ${ }^{\circ} 8181$, então com a denominação de Instituto Brasileiro de Turismo, a EMBRATUR tem uma única finalidade promover o Brasil no exterior.

Em 1\%101/2003 foi instituiu pela MPV $N^{\circ} 103$, convertida na Lei $n .^{\circ} 10.683$, de 28/05/2003, art. 30, inciso X, cria o Ministério do Turismo, e o art. 27, inciso XXIII, trata das áreas de competência desse Ministério. O art. 33, inciso IX, transfere o Conselho Nacional de Turismo do Ministério do Esporte e Turismo para o Ministério do Turismo. $\mathrm{O}$ art. 35 cria o cargo de Ministro de Estado do Turismo.

E esse tem como missão "desenvolver o turismo como uma atividade econômica sustentável com papel relevante na geração de empregos e divisas, proporcionando a inclusão social. O Ministério do Turismo inova na condução de políticas públicas com um modelo de gestão descentralizado, orientado pelo pensamento estratégico".

Espera-se que o turismo, alicerçando nas potencialidades do maior país tropical do mundo, possa cooperar de forma substantiva como instrumento de desenvolvimento regional sustentável, alcançando resultados expressivos para o país. 
Dentre esses resultados, destacam-se: a melhoria da qualidade de vida de milhões de brasileiros que vivem em regiões com reconhecido potencial turístico; a integração socioeconômica e cultural da população; a proteção do meio ambiente e o patrimônio histórico e cultural; a geração de novos empregos e frentes de trabalho e o maior aporte de divisas para o país.

\begin{tabular}{ll}
\hline ANO & CHEGADAS \\
\hline 1970 & 249.900 \\
1975 & 517.967 \\
1980 & 1.625 .422 \\
1986 & 1.934 .091 \\
1990 & 1.091 .067 \\
1992 & 1.692 .078 \\
1993 & 1.641 .138 \\
1994 & 1.853 .301 \\
1995 & 1.991 .416 \\
1996 & 2.665 .508 \\
1997 & 2.849 .750 \\
1998 & 5.530 .000 \\
1999 & 5.690 .000 \\
2000 & 5.780 .000 \\
2001 & 4.800 .000 \\
2002 & 3.800 .000 \\
\hline & \\
\hline
\end{tabular}

Tabela 2 - Chegada de Turistas Estrangeiros no Brasil 
Fonte: EMBRATUR - Instituto Brasileiro de Turismo, Anuário Estatístico 2003.

A partir de 1980, grandes contingentes passam a viajar. No turismo internacional, o Brasil sempre apresentou desempenho fraco no que diz respeito à entrada de estrangeiro (tabela 2).

No tocante à saída de turistas brasileiros para o exterior, a partir de 1994, dá-se de forma mais intensa superando a entrada de estrangeiros (tabela 3).

\begin{tabular}{|c|c|}
\hline ANO & SAÍDAS \\
\hline 1980 & 427.416 \\
\hline 1990 & 1.095 .233 \\
\hline 1991 & 1.149 .831 \\
\hline 1992 & 1.158 .392 \\
\hline 1993 & 1.222 .951 \\
\hline 1994 & 1.876 .530 \\
\hline 1995 & 1.746 .898 \\
\hline 1996 & 3.397.249 \\
\hline 1997 & 4.014 .340 \\
\hline 1998 & 4.171.110 \\
\hline 1999 & 2.862.754 \\
\hline 2000 & 2.888 .400 \\
\hline 2001 & 2.268.611 \\
\hline 2002 & 1.860 .817 \\
\hline
\end{tabular}

Tabela 3 - Saídas de turistas brasileiros 


\section{Fonte: Embratur, 2003}

Vale destacar os anos de 1996 e 1997 que as saídas superam as entradas em até 100\%. Assim, investimentos merecem serem feitos no âmbito do turismo, sejam em divulgações ou em estrutura, de maneira a instigar o turista brasileiro a fazer viagens de turismo no Brasil.

O turismo por ser uma atividade de grande alcance apresentou ao longo dos anos vários conceitos e diversas interpretações. Diversos autores apresentam as suas versões.

Para Barreto (1995) o conceito de turismo surge no século XVII na Inglaterra, referido a um tipo de especial de viagem. A palavra tour é de origem francesa, como muitas palavras do inglês moderno que definem conceitos ligados à riqueza e à classe privilegiada. A palavra tour quer dizer volta e tem seu equivalente no inglês turn, e no latim tornare

Para Lickorish e Jenkins (2000) o turismo é basicamente um movimento de pessoas, uma força de demanda, e não uma simples indústria. Na língua inglesa os turistas eram referidos como viajantes. Recentemente, turismo se tornou o termo universal que descreve o movimento de pessoas que saem do local de sua residência permanente para um estada temporária em outro local.

De acordo com Gianini (1993) o economista Inglês Norval conceitua turista sob aspectos econômicos e de visitantes estrangeiros. Diz que qualquer viajante que gasta seu dinheiro num país estrangeiro é um turista. Qualquer pessoa que venha a um país estrangeiro com o fim diferente ao de fixar residência 
permanente ou de trabalhar e que gasta nesse país de sua estada temporal o dinheiro que ganhou em outra parte.

Em 1937, a Comissão Econômica da Sociedade das Nações definiu o termo turista como pessoa que viaja por uma duração de 24 horas ou mais em um cidade diferente daquela em que tem sua residência habitual. Pode ser chamada de turista a pessoa que realiza viagens por: prazer, motivos de família e de saúde; para participar de reuniões, congressos, seminários e encontros de toda ordem, sejam administrativos, diplomáticos, científicos, religiosos, desportivos; por motivo de negócio, e os participantes de cruzeiros marítimos, embora com duração de estada, inferior a 24 horas.

Não são considerados turistas, pela mesma Sociedade das Nações, as pessoas que viajam para: ocupar emprego no país visitado, exercendo atividade profissional; fixar residência no país, as pessoas que residem na fronteira e trabalham num país vizinho; estudantes que moram em pensões ou estabelecimentos de ensino; pessoas em trânsito que não se detêm no país por mais de 24 horas.

A União Internacional dos Organismos Oficiais de Turismo (UIOOT), atual Organização Mundial do Turismo, tentou unificar várias definições propondo à comissão de Estatística da Organização das Nações Unidas, que foi aprovado em 1968, designado pelo termo genérico de visitante "qualquer pessoa que vá a um país que não é aquele em que tem residência habitual, por qualquer outra razão que não seja a de exercer uma profissão remunerada nesse mesmo país" (GIANINI, 1993:). 
Separou, ainda, os visitantes em duas categorias: os turistas e os excursionistas.

Definir turismo é bem mais complexo do que simplesmente definir o turista, por ser um conjunto interligado de fenômenos, que visam diretamente ou indiretamente o mesmo fim, envolvendo toda uma gama de recursos naturais, históricos, culturais, sociais e de estrutura básica específica, que contracena com a demanda consumidora em permanente deslocamento.

Aos peritos e pesquisadores de Turismo, as terminologias turísticas denominadas específicas ainda se apresentam como passíveis de reformulações, pois, além de apresentarem algumas inexatidões, são expressões de alcance amplo, fato que impede a tradução e o dimensionamento exato das teorias e das técnicas que o fenômeno encerra em seus princípios e em suas operações. Independente das inexatidões e das inseguranças teóricas. É o fenômeno que mais progride à medida que a economia e as finanças, aliadas aos interesses humanos, procuram respostas satisfatórias às várias necessidades naturais de provimento de carências e de correspondência a desejos lícitos e exigências de melhor conhecimento do mundo e das pessoas.

Esses anseios levam um número sempre maior de indivíduos e de grupos a viajar mais, por meio de múltiplas rotas novas para o conhecimento de novos lugares.

Para Andrade (1998) turismo é o conjunto de serviços que tem por objetivo o planejamento, a promoção e a execução de viagens, e os serviços de recepção, hospedagem e atendimento aos indivíduos e aos grupos, fora de suas residências habituais. 
Já Lickorish e Jenkins (2000) consideram o turismo como uma soma de fenômenos e relacionamentos que surgem das viagens e de estadas de indivíduos não-residentes, na medida em que não visam a uma residência permanente e não são ligados a atividades remuneradas.

Característico de uma sociedade de consumo, o turismo como um todo estruturado não é mais do que um produto composto ou uma combinação de bens e de serviços, cuja funcionalidade depende de uma série de conhecimentos operacionais e de paciente dedicação para atendimento de requisitos da oferta e das exigências da demanda.

\subsection{MARKETING DE SERVIÇOS}

O setor de serviços já detém a maior participação no PIB dos países desenvolvidos e em muitos dos países em desenvolvimento. Além disso, é o setor que atualmente, mais emprega mão-de-obra. Os serviços hoje no Brasil representam mais de $55 \%$ da economia brasileira, ou seja, mais da metade da produção e dos empregos brasileiros provém de serviços.

O marketing de serviço tem como foco três principais dimensões: a) os clientes atuais e potenciais; b) os funcionários; e c) a interação cliente-prestador de serviço, a chamada "hora da verdade". Somente quando essas três dimensões são bem atendidas é que o marketing de serviço pode alcançar os resultados desejados. 
As necessidades dos clientes vêm antes dos produtos e dos serviços. Não é possível inverter a ordem do processo. O cliente, o consumidor, mais do que nunca, está indicando o "norte" para as empresas. É a partir dele e de suas necessidades e seus desejos, que produtos e serviços precisam ser concebidos. Definitivamente não está disposto a aceitar o que a ele tentarem empurrar.

Podemos considerar inúmeras diferenças entre tratar a Administração Mercadológica de Produtos e a de Serviços. Comecemos pela principal - o momento da produção. No Mercado de Produtos, as mercadorias são, em geral, produzidas antes de serem vendidas. O que possibilita a execução do controle de qualidade antes da entrega ao cliente. No Mercado de Serviços, a venda ocorre antes da produção. Em outras palavras, isso quer dizer que no mercado de produtos o consumidor pode ter contato físico com a mercadoria antes de ter a posse desta mercadoria enquanto que no de Serviços o consumidor compra uma promessa de entrega de Serviços. Ele compra uma promessa que só vai ser concluída com a experiência do serviço pretendido, como, por exemplo, em um show.

Para conhecer um serviço, portanto, o cliente tem de experimentá-lo já na situação de usuário, já na situação de compra realizada. Por isso, a percepção de risco tende a ser muito elevada nos serviços, pois eles não podem ser tocados, cheirados, degustados ou até mesmo provados antes do ato da compra. 
No Mercado de Serviços, portanto, a percepção da qualidade é fortemente influenciada pela experiência, um atributo que só pode ser avaliado depois do "uso" do serviço.

A qualidade do Serviço é à base do Marketing de Serviços, enquanto no Marketing de Produtos é o seu desempenho.

\subsection{CONCEITO DE SERVIÇOS}

A principal característica das últimas décadas é a velocidade das mudanças, colocando para as organizações o grande desafio de acompanhá-las e de antevê-las, para melhor se estruturarem no futuro. As mudanças no mercado, aliadas às necessidades das organizações alcançarem melhores níveis de desempenho organizacional, não somente para o bem-estar da própria organização, mas principalmente pela importância do seu papel desempenhado na sociedade, evidenciam uma conscientização quanto à necessidade de qualidade no processo de prestação de serviço e não só com os produtos vendidos.

Theodore Levitt, citado por Kotler (1998:411), registrou que "não existe o que se chama indústria de serviços. Há apenas setores industriais cujos componentes de serviços são maiores em relação a outros setores. Todos estão na área de serviço".

Para Kotler (1998, p.412), "serviço é qualquer ato ou desempenho que uma parte possa oferecer a outra e que seja essencialmente intangível e não resulte na 
propriedade de nada. Sua produção pode ou não estar vinculada a um produto físico".

A Associação Americana de Marketing define serviços como as atividades, vantagens ou mesmo satisfações que são oferecidas à venda ou que são produzidas em conexão com a venda de mercadorias. R. C. JUDD (1966) classifica o serviço como uma transação de mercado realizada por uma empresa ou por um empresário, na qual o objeto de transação não está associado à transferência de propriedade de um bem tangível. (Toledo, 1978:19)

Kotler (1998) define serviço como uma ação ou performance que uma parte pode oferecer a outra, essencialmente intangível, e não resulta na possessão de nada. Sua produção pode ou não estar relacionada a um produto físico.

Nos ambientes altamente competitivos em que os serviços atuam (onde se enquadra a indústria bancária brasileira), a estratégia de diferenciação enfocando inovação e um aspecto suplementar do produto é mais adequado, inclusive com benefícios para a construção de uma reputação de longo prazo.

Nota-se que ainda hoje as empresas e serviços estão, em geral, mais orientadas para o "processo" do que para o consumidor. Uma conduta empresarial voltada para o marketing possibilita as empresas de serviço agir mais rapidamente no sentido de capitalizar novas oportunidades de mercado, em vez de se concentrar na tentativa de criar demandas para os serviços já existentes.

A estratégia de serviços significa criar uma série de serviços que ressaltem o relacionamento com os clientes. Uma estratégia de serviços não apenas permite que a empresa diferencie sua oferta e crie um valor agregado para seus clientes, 
mas, também, ajuda a manter os concorrentes longe desse relacionamento com clientes.

"Uma característica adicional nas interações entre o comprador e vendedor de serviços é que os clientes participam da produção" (Cobra, 1992:373). É sabido que um serviço a um cliente não é exatamente este mesmo serviço ao próximo cliente. O serviço que um cliente recebe utilizando um caixa automático bancário pode diferir do "mesmo serviço" recebido pelo próximo cliente porque, por exemplo, a segunda pessoa pode demonstrar dificuldade em compreender as instruções na tela ou necessitar de uma operação diferente das oferecidas (Gronroos, 1995:40).

Há também a crescente necessidade de informação dos consumidores. Para McKenna (1993:), em quase todos os casos as informações sobre serviços são um componente crucial do produto. Segundo ele, o novo marketing exige um ciclo de feedback, conectando a empresa e o cliente.

O motivo do sucesso em qualquer empresa é o grau de relacionamento da empresa com seus clientes. Essa integração depende do bom atendimento da clientela, portanto, prestar serviços com qualidade significa estreitar com os clientes um importante elo, chamado boa vontade. Cliente satisfeito sempre terá boa vontade para com seus fornecedores, mesmo quando existe um problema, que bem resolvido funciona como um fidelizador de clientes. Fica claro que sem um bom atendimento o desenvolvimento e até a manutenção do relacionamento é quase impossível. 


\subsection{TIPOS DE SERVIÇOS}

De acordo com Las casas (2002:), os serviços podem ser classificados, no que diz a respeito ao esforço em obter os serviços. E nesse sentido, há dois tipos de serviços os de consumo e os industriais.

\subsubsection{Serviço de Consumo}

São aqueles prestados diretamente ao consumidor final. Nessa categoria, eles subdividem-se em:

De conveniência - ocorre quando o consumidor não quer perder tempo em procurar a empresa prestadora de serviços por não haver diferenças perceptíveis entre elas.

De escolha -- caracteriza-se quando alguns serviços têm custos diferenciados, de acordo com a qualidade e tipo de serviços prestados, prestigio da empresa, etc. Nesse caso, compensará ao consumidor visitar diversas firmas na busca de melhores negócios.

De especialidade — são aqueles altamente técnicos e especializados. consumidor, nesse caso, fará todo o esforço possível para obter serviços de especialistas.

\subsubsection{Serviços Industriais}

São aqueles prestados as organizações industriais, comerciais ou institucionais. Nessa categoria, podem ser: 
De equipamentos - são serviços relacionados com a instalação, montagens de equipamentos ou manutenção.

De facilidade — nesse caso estão incluídos os serviços financeiros, de seguros, etc., pois facilitam as operações da empresa.

De consultoria / orientação - são aqueles que auxiliam nas tomadas de decisão e incluem serviços de consultoria, pesquisa e educação.

3.6 Características dos Serviços

De acordo com Lovelock e Wright (2005), existem diferenças básicas entre os bens e os serviços e a principal distinção é que "bens podem ser descritos como objetos ou dispositivos físicos enquanto que os serviços são ações ou desempenho" .

Os Programas de Marketing são muito afetados por estas quatro características: Intangibilidade, Inseparabilidade, Variabilidade e Perecibilidade.

\section{Intangibilidade}

Serviços não podem ser vistos, provados, sentidos, ouvidos ou cheirados.

O desafio para a área de marketing é a de "evidenciar" a qualidade dos Serviços procurando, de alguma forma, tangibilizar esse serviço. 
Inseparabilidade

Diferente dos Produtos, os Serviços são produzidos, entregues e consumidos simultaneamente, chegando a fazer parte de uma pessoa quando o mesmo é por ela prestado.

A inseparabilidade traz, como uma de suas conseqüências, a presença do cliente aumentando em muito a preocupação com sua satisfação imediata.

\section{Variabilidade}

Um serviço a um cliente não é exatamente este "mesmo serviço" ao próximo cliente. Essa é a característica da variabilidade ou heterogeneidade. E é a causa de um dos maiores problemas no gerenciamento dos serviços como manter uma qualidade uniforme percebida dos Serviços produzidos e entregues aos clientes?

\section{Perecibilidade}

Esta também é uma característica problemática. Os Serviços não podem ser estocados, obrigando para o gestor uma grande necessidade de estabelecer equilíbrio entre a demanda e a oferta.

Um lugar (assento) de avião que não foi ocupado naquele vôo não pode ser guardado (estocado) para o próximo vôo. O restaurante executivo com fila de 
espera na hora do almoço não pode fazer os clientes esperarem (estocar clientes ou esperar demanda futura). Esse mesmo restaurante que teve ocupação de 50\% de suas mesas hoje não poderá servir amanhã o prato do dia de hoje.

\subsection{Componentes do Pacote de Serviços}

São quatro os Componentes do pacote de Serviços:

1. As instalações de Apoio dizem respeito ao local que está instalado ou que necessita para que seja realizado o serviço. Pode ser, também, um equipamento que dá suporte ao Serviço. É por meio das instalações de apoio que boa parte da "primeira impressão" sobre o serviço é construído na mente do cliente. A instalação de apoio é uma das partes tangíveis do serviço.

2. Os Bens Facilitadores são aqueles que auxiliam a execução do Serviço ou que dão suporte e eles.

3. Os Serviços explícitos são exatamente o que se espera receber com aquele serviço.

4. Os serviços Implícitos, tudo o que está em volta do serviço propriamente dito e diz respeito ao que percebo ou obtenho por meio do uso daquele serviço. 


\subsection{Distribuição dos Serviços}

A distribuição de serviços implica, quase sempre, a distribuição de custos fixos. Distribuir serviços requer a disponibilidade dos mesmos no momento em que o cliente precisa, visto que serviços não são estocáveis.

Além disso, distribuir serviços requer, muitas vezes, a distribuição da cultura do serviço, o que não é fácil de ser reproduzido. Ou seja, a decisão de distribuição de serviço é complexa, exige custos e planejamento apurados e costuma não ser uma distribuição pulverizada, mas concentrada.

Distribuir um produto é o equivalente a vendê-lo, mas no setor de serviços é preciso primeiro construir uma estrutura para atender a uma possível demanda.

Uma mudança importante nesse aspecto da distribuição de serviços tem sido o crescimento dos canais eletrônicos, notadamente os call centers ${ }^{2}$ e a internet, que permitem a pulverização do contato, mantendo o controle e o custo em uma mesma plataforma. Não é sem razão que os bancos investem nesse mercado.

Nesses canais que reduzem seus custos de investimento e de operação, agregando valor ao cliente pelo aumento da disponibilidade. 


\subsection{Comunicação nos serviço}

Dentro do Marketing Mix, vamos encontrar os Quatros Ps: Produtos, Preço, Praça (de local, de distribuição) e Promoção (de comunicação).

Promoção, no sentido de comunicação, é toda e qualquer forma de comunicação que a empresa realiza com seus diversos públicos.

São diversas as Ferramentas de Comunicação: Propaganda, Publicidade, Relações Públicas, Venda Pessoal, Marketing Direto, Promoções e Merchandising. Podemos aprofundar nosso conhecimento sobre elas:

Propaganda: é uma forma de comunicação impessoal, unilateral, paga e assumida pelo anunciante.

Publicidade: é a estratégia de comunicação que explora o caráter informativo da comunicação, criando fatos, provocando notícias, desenvolvendo a formação da imagem da empresa.

Relações Públicas: busca obter publicidade favorável e ampla, trata da imagem institucional e de sua identificação.

Venda Pessoal: qualquer forma de apresentação pessoal com compradores potenciais, tendo o propósito de realizar vendas.

Marketing Direto: é um sistema interativo que usa uma ou mais mídias de propaganda para obter uma resposta e/ou transação mensurável em qualquer localização.

Promoções de vendas: é a atividade mercadológica em que é ofertado um benefício extra e temporário ao consumidor, para induzir o ato da compra. 
Merchandising: é uma atividade mercadológica que se destina a conduzir os canais por meio dos canais de distribuição.

Um bom roteiro de construção de uma Estratégia de Comunicação passa pela:

- Identificação da audiência-alvo (ou público-alvo).

- Determinação dos objetivos de comunicação.

- Preparação da mensagem.

- Decisão sobre os canais de comunicação.

- Decisão sobre o composto de comunicação.

- Administração e coordenação do processo global de comunicação e marketing.

- Medição dos resultados.

Para obter um bom resultado, o consumidor deve selecionar canais eficientes de comunicação para veicular a mensagem. Os canais de comunicação são de dois tipos amplos: pessoal e impessoal.

Canais de Comunicação Impessoal: são dois canais que conduzem mensagens sem contato ou interação pessoal. Incluem a mídia, atmosferas e eventos.

Canais de Comunicação Pessoal: envolvem duas ou mais pessoas comunicando-se diretamente entre si. Elas podem comunicar-se face a face, corpo a corpo com a audiência, por telefone ou pelo correio. Os canais de comunicação pessoal são considerados eficazes pelas oportunidades que têm de individualizar a apresentação e o feedback. 
O Serviço de Atendimento ao Cliente, o SAC, é uma das formas de comunicação mais eficientes para as empresas de Serviços. É um meio que permite ao cliente expressar o que for necessário e à empresa, reagir individualmente em cada caso.

\section{GESTÃO DA QUALIDADE DOS SERVIÇOS}

O conceito de qualidade evolui sempre acompanhando o ritmo das mudanças. Inicialmente, foi utilizado o termo Controle de Qualidade que se valia de técnicas de controle estatístico visando à redução da quantidade de produtos defeituosos. Após a Segunda Guerra Mundial, foi adotado o controle de processos, que englobava toda a produção, do projeto ao acabamento, objetivando a segurança e o alcance do erro zero. Para Maximiano (2000:), esse conceito de Controle do Processo evoluiu para Garantia da Qualidade, com a sistematização por meio de normas escritas, dos padrões e requisitos, em cada etapa do processo produtivo, de forma a garantir boa e uniforme qualidade.

Para Crosby (1992), qualidade é a conformidade com as especificações. Quando você tenciona fazer certo da primeira vez, todos devem saber o que isso significa. A qualidade se encontra na prevenção que, por sua vez, se origina do treinamento, disciplina, exemplo, liderança e persistência. O padrão do desempenho da qualidade é o zero defeito, ou seja, os erros não são tolerados. A medida da qualidade é o preço da não-conformidade. 
Deming (1990) relata que qualidade não é um luxo, mas, sim, aquilo que o cliente deseja sempre, necessita e quer. Como os desejos dos clientes sempre estão mudando, a solução para definir qualidade é redefinir constantemente as especificações.

Já para Feigenbaum (1994), a qualidade é um modo de vida corporativo, uma maneira de gerenciar que requer a participação de todos, pois o controle de qualidade total produz impacto por toda a empresa. A qualidade total deve ser guiada para a excelência e não pelos defeitos.

Para Juran (1990), qualidade é a adequação ao uso. Um dos significados de qualidade é o desempenho do produto cujas características proporcionam a satisfação dos clientes que irão comprá-lo. Seria, por outro lado, a ausência de deficiências, pois estas geram insatisfação e reclamações dos clientes.

Para Juran (1990), a Qualidade de Serviços é conceituada de acordo com a opinião dos clientes e, na busca por competitividade e melhoria contínua, as organizações devem ter esse conceito suficientemente claro na tomada de decisões. Em serviços, o cliente é o elemento central da produção, sendo ele o decisor em termos de onde, como e quando esta deva se realizar. Uma organização deve considerar cliente todo aquele que a freqüenta, "consumindo" quaisquer de seus serviços, sofrendo qualquer tipo de impacto ou influência ou mantendo qualquer tipo de contato com pessoa ou setor da empresa. No caso de uma agência bancária, por exemplo, nem todos que passam por sua porta ou mesmo a freqüentam possuem vínculos como conta corrente, poupança ou investimentos na mesma; contudo os mesmos devem ser considerados "clientes 
potenciais" desta agência, pois podem usufruir seus serviços diversos por conveniência ou necessidades pessoais.

Assim, na busca de serviços voltados para o cliente, cada organização deve, primeiro, conhecê-los, saber o que eles querem, o que consideram imprescindível em sua avaliação do serviço e como enxergam os serviços que lhe são prestados. Por isso, entender quem são eles é fundamental para a empresa poder oferecer um serviço com qualidade que satisfaça aos clientes.

"Uma característica adicional nas interações entre o comprador e vendedor de serviços é que os clientes participam da produção" (Cobra, 1992, p.373). É sabido que um serviço a um cliente não é exatamente este mesmo serviço ao próximo cliente. Para Gronroos (1995:40), o serviço que um cliente recebe utilizando um caixa automático bancário pode diferir do "mesmo serviço" recebido pelo próximo cliente porque, por exemplo, a segunda pessoa pode demonstrar dificuldade em compreender as instruções na tela ou necessitar de uma operação diferente das oferecidas. A pronta resposta a reclamações, a rápida manutenção ou reparo são alguns exemplos de atendimento, é preciso descobrir o que os clientes valorizam na qualidade do atendimento.

Em cada tipo de negócio se estabelecem parâmetros de qualidade, embora o conceito seja muitas vezes subjetivo ou mesmo intuitivo. O que é qualidade para um cliente poderá não ser para outro. A pronta resposta a reclamações, a rápida manutenção ou reparo são alguns exemplos de atendimento, é preciso descobrir o que os clientes valorizam na qualidade do atendimento (Berry e Parasuraman, 1992:).

O serviço funciona como uma forma de proteção à imagem da empresa. 
Sem a qualidade do serviço, a marca fica desprotegida. Para Wellington (2001:), a verdadeira e eficaz definição de "qualidade" é aquela que vem acompanhada dos valores e princípios que a organização se compromete a respeitar; como estes, por exemplo:

1 - Valores

$\checkmark$ agir sempre com justiça e lealdade;

$\checkmark$ dar efetiva primazia ao cliente;

$\checkmark$ oferecer serviços competentes e atenciosos;

$\checkmark$ promover melhor condição possível do corpo, da mente e do espírito;

$\checkmark$ criar um clima de produtividade crescente;

$\checkmark$ incentivar a comunicação, a colaboração e o intercâmbio.

2 - Princípios

$\checkmark$ a qualidade é conseguida (produzida) por meio das pessoas;

$\checkmark$ a decisão deve ser fundamentada em fatos;

$\checkmark$ os clientes são a prioridade número um;

$\checkmark$ a qualidade exige melhoria contínua;

$\checkmark$ todo trabalho é parte de um processo.

Cabe ressaltar que não é só por resultados econômicos financeiros que a qualidade deve ser buscada, e sim porque ela:

$\checkmark$ respeita e valoriza quem presta o serviço;

$\checkmark$ respeita o cliente que o utiliza; 
$\checkmark$ respeita e valoriza a própria organização que a produz.

Os serviços são de boa qualidade quando vão de encontro aos anseios e necessidades dos clientes. Um serviço é uma forma de ampliar um produto vendido. Mas pode tanto ser um fator chave para o sucesso como ao contrário ser um fator crítico de fracasso estratégico. "Assim como a propaganda em longo prazo constrói a imagem de marca, o bom serviço vale mais que mil palavras na construção da imagem de um produto ou de uma empresa na mente do consumidor". (Rangel e Cobra, 1993:).

De acordo com Wellington (1998), por causa da importância da qualidade em indústrias de serviço, nós necessitamos compreender melhor como os clientes avaliam os serviços prestados e como suas avaliações afetam suas percepções da qualidade total do serviço, do fornecedor de serviço e de sua própria satisfação. Nesse sentido, o autor, propõe um modelo da qualidade do serviço que ligue opções de serviço percebidas pelo cliente às dimensões tradicionais do serviço como medidas por SERVQUAL no contexto da qualidade do serviço e da satisfação de cliente.

Assim, complementam os autores, que compreendendo como os clientes avaliam opções de serviços prestados e que fatores afetam suas avaliações, os fornecedores de serviço estarão em uma posição melhor para desenvolver, promover e conseguir um nível mais elevado da qualidade do serviço e da satisfação de clientes. 


\title{
CONSIDERAÇÕES FINAIS
}

\begin{abstract}
Partindo dos conceitos apresentados nesse trabalho e, ainda, considerando o tema proposto, considerar-se-á bastante relevante as metas traçadas nos objetivos gerais e específicos no sentido de que a importância do ramo de serviços no Marketing tomou proporções muito desenvolvidas, sobretudo se pensarmos nos aspectos do profissional do turismo como elemento potencializador desse marketing de serviços.
\end{abstract}

Outro aspecto a ser relevado foi exatamente a discussão de que o serviços não podem ser estocados, haja vista que os níveis de produção são totalmente diferentes dos demais produtos oferecidos no Turismo. Dessa forma, conforme o tipo de metodologia adotado e, também, diante dos variados obstáculos aqui encontrados, pode-se dizer que, além do Turismo constituir um fator indispensável ao aspecto econômico nacional, gerando, assim, divisas para o país, o Turismo proporciona renda, trabalho a muitas pessoas que, de uma forma ou de outra, deixam esse setor como uma atividade primordialmente primária na escala de produção.

Por derradeiro, tem-se a perspectiva de que, indiretamente, todos os objetivos foram alcançados, somente considerando, para tanto, que a prática do marketing de serviços na gestão do profissional de turismo, além da proporção abrangente e integrada da gestão de serviços constituem, ao final, aspectos positivos e propagadores de uma melhor qualidade nos serviços que, direta ou indiretamente, envolvam as atividades turísticas. 


\section{REFERÊNCIAS BIBLIOGRÁFICAS}

ANDRADE, Jose Vicente de. Turismo: Fundamentos e dimensões. 3. ED. São Paulo: Ática, 1997. 215 p.

ASSUNCAO FILHO, Moacir Assis D'; CARVALHO, Vicentina Cornélio de; GOMES, Wellington Caldeira. Ciências naturais numa visão sociointeracionista. São Paulo: Inst Brás Ed Pedagog, 2001. 4 v. ISBN 85-3420636-8.

COBRA, Marcos Henrique Nogueira. Administração de marketing. 2. ed. São Paulo: Atlas, 1992. 806 p. ISBN 85-224-0769-x.

COBRA, Marcos Henrique Nogueira; ZWARG, Flavio Arnaldo. Marketing de serviços: Conceitos e estratégias. São Paulo: Mcgraw-Hill, 1986. 284 p.

CROSBY, Philip B. Liderança: A arte de tornar-se um executivo. Sao Paulo: Makron Books Brasil, 1991. 224 p.

DEMING, William Edwards. Qualidade: A revolução da administração. Rio de janeiro: Marques-Saraiva, 1990. $367 \mathrm{p}$.

FEIGENBAUM, Armand V. Controle da qualidade total. São Paulo: Makron Books Brasil, 1994. v ISBN 85-346-0156-9.

GIANINI, Vera Lucia Veloso. Marketing hoteleiro. 2002. 47 p.

GRONROOS, Christian. Marketing: gerenciamento e serviços. Rio de janeiro: Campus, 2003. 482 p. ISBN 8535212590.

IGNARRA, Luiz Renato.Fundamentos do turismo. São Paulo: Pioneira, 200. 135 p. ISBN 85-221-0171-X.

JURAN, Joseph M; GRYNA, Frank M.Controle da qualidade. Sao Paulo: Makron Books Brasil.

KOTLER, Philip. Administração de marketing: Analise, planejamento, implementação e controle. 5. ed. São Paulo: Atlas, 1998. 7250 p.

KOTLER, Philip. Marketing para o século XXI: Como criar, conquistar e dominar mercados. 6. ed. São Paulo: Futura, 2000. 305 p. ISBN 85-7413-004-4.

LEVITT, Theodore. Marketing para desenvolvimento dos negócios. São Paulo: Cultrix $297 \mathrm{p}$. 
LICKORISH, Leonard J; JENKINS, Carson L. Introdução ao turismo.Rio de janeiro: Campus, 2000. 317 p. ISBN 85-352-0688-4.

MAXIMIANO, Antonio César Amaru.Teoria geral da administração:Da escola cientifica a competitividade em economia globalizada. São Paulo: Atlas, 1997. 371 p.

MCCARTHY, Edmund Jerome; PERREAULT, William D Marketing essencial: Uma abordagem gerencial e global. 6. ed. São Paulo: Atlas, 1997. 397 p.

RICHERS, Raimar. Que e marketing(o). 15. ed. São Paulo: Brasiliense, 2001. $107 \mathrm{p}$.

RUSCHMANN, Doris Van de Meene. Turismo e planejamento sustentável: A proteção do meio ambiente. 3. ed. Campinas: Papirus, 1999. 199 p. ISBN 85308-0439-2.

TOLEDO, Flavio de. Administração de pessoal: Desenvolvimento de recursos humanos . 8. ed. São Paulo: Atlas, 1992. 294 p. ISBN 85-224-0763-0.

TRIGO, Luiz Gonzaga Godoi. Turismo e qualidade: Tendências contemporâneas. 5. ed. Campinas: Papirus, 1999. 120 p.

VAZ, Gil Nuno. Marketing turístico: Receptivo e emissivo. São Paulo: Pioneira, 1999. 296 P ISBN 85-221-0198-1. 